\title{
Research Paper: Construction and Validation of Emotional Divorce Scale in Iranian Population
}

\author{
Fereshteh Mirzadeh Koohshahi ${ }^{1}$ (D), Alimohamad Rezaei ${ }^{2 *}$ (D), Mahmoud Najafi ${ }^{1}$ (D)
}

1. Department of Psychology, Faculty of Psychology \& Educational Sciences, Semnan University, Semnan, Iran

2. Department of Educational Sciences, Faculty of Psychology \& Educational Sciences, Semnan University, Semnan, Iran.

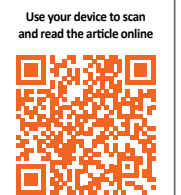

Clftation Mirzadeh Koohshahi, F., Rezaei, A., \& Najafi, M. (2019). Construction and Validation of Emotional Divorce Scale in Iranian Population. Journal of Practice in Clinical Psychology, 7(1), 53-62. http://dx.doi.org/10.32598/jpcp.7.1.53

doi http://dx.doi.org/10.32598/jpcp.7.1.53

\section{(i) (3)}

Article info:

Received: 10 Feb 2018

Accepted: 05 Sep 2018

Available Online: 01 Jan 2019

Keywords:

Divorced, Emotion, Factor analysis, Psychometrics

\section{ABSTRACT}

Objective: Divorce is one of the social problems and underlying factors of many psychological problems, thereby demanding necessary research to prevent its occurrence. This study aimed to construct and validate Emotional Divorce Scale in Iranian couples.

Methods: This was a cross-sectional research. A total number of 400 married individuals living in east part of Tehran City, Iran between May and June 2016 were selected by random cluster sampling method and responded to the research instruments (researcher-made Emotional Divorce Scale, Dr. Phil Relationship Health Profile Test, and Enrich Marital Satisfaction Scale). Data analyses were performed by factor analysis, Pearson correlation coefficient, and Cronbach alpha coefficient in SPSS V. 22 and LISREL V. 8.80.

Results: The results of factor analysis showed that Emotional Divorce Scale comprised three factors. The three-factor structure of the scale was confirmed by goodness-of-fit indices. The results of Pearson correlation indicated that the total score of Emotional Divorce Scale was significantly correlated with relationship health profile test (0.69) and Enrich Marital Satisfaction Scale (-0.42) at significance level of 0.01 . The internal consistency of the total scale was 0.97 and the internal consistency of the three factors, namely compulsory living, absence of romantic behavior towards spouse, and emotional vacuum were $0.97,0.73$, and 0.93 , respectively.

Conclusion: Finally, the Emotional Divorce Scale enjoys acceptable psychometric properties regarding the ease of administration, scoring, and interpretation, as well as suitable validity and reliability of the questionnaire. Thus, researchers can safely use it in their studies.

\footnotetext{
* Corresponding Author:

Alimohamad Rezaei, $P h D$

Address: Department of Educational Sciences, Faculty of Psychology \& Educational Sciences, Semnan University, Semnan, Iran.

Tel: +98 (912) 4498984

E-mail:rezaei_am@semnan.ac.ir
} 


\section{Highlights}

- The emotional divorce scale has acceptable psychometric properties.

- It is easy to administrate, score, interpret, and has suitable validity and reliability.

- It is a proper instrument for the assessment of emotional divorce among couples.

- The experts can identify the people at risk of divorce by this instrument and prevent it via taking necessary measures.

\section{Plain Language Summary}

A crisis like divorce trembles family foundation and creates negative emotions in the family, especially among children. Based on the research, the children with separated parents suffer from a lot of problems at school, such as behavioral problems, negative attitudes toward themselves, and conflicts with peers and parents compared to normal children. Divorce can cause many other social problems like addiction, crime, psychosis, personality conflicts, and major depression.

Emotional divorce is a latent and unregistered phenomenon in the life of many couples in which they are not officially separated; however, they live together just as roommates without any feeling and emotion to one another. Emotional divorce is the first step in the formal divorce process; therefore, it is possible to prevent formal divorce by the identification of emotional divorce and provision of appropriate tools to identify couples with emotional divorce. Hence, a scientific instrument is needed to detect emotional divorce based on Iranian culture. In this study, a valid and reliable scale was developed for measuring emotional divorce for Iranian couples

\section{Introduction}

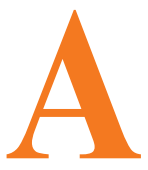

$\mathrm{s}$ the first social unit and the most important determinant of child behavior, family has drawn the attention of researchers in psychology, sociology, and education (Fouladchang, 2006).

Healthy families create a healthy environment for the well-being of the couples and the proper raising of children. A healthy society is based on healthy families and those men and women, who are aware of their duties and responsibilities, are the cornerstones of healthy families. Such individuals act as if they follow the correct rules and principles. Negligence and disregard of duties or changing/mixing the roles are detrimental to family life, and thereby damaging the society (Rezayi \& Naraghi, 2010).

A crisis like divorce trembles family foundation and creates negative emotions in the family, especially among adolescents (Feldhaus \& Heintz-Martin, 2015). Therefore, the collapse of marriage creates egregious negative consequences for divorcees and their children (Amato, 2010). Based on the research, the children whose parents are divorced suffer from a lot of problems at school, such as behavioral problems, negative atti- tudes toward themselves, and conflicts with peers and parents compared to normal children (Etzion \& Romi, 2015). Of course, not all children of divorce will suffer from these problems, but a high number of them become involved with such problems.

These children feel more discomfort and even struggle with such problems by the end of adolescence (Hamama \& Ronen-Shenhav, 2012). It seems that the adolescents who live in single-parent homes are more likely to be exposed to maladaptive behaviors than non-smokers (Okorodudu, 2010).

The poor performance of separated parents can propel adolescents to participate in risky behavior, lead to their reduced quality of life, and a decrease in happiness and life satisfaction (Koerner \& Maki, 2004). In the same way, living away from family and limited family interactions put adolescents at risk of identity crisis; communication, personal and social problems; and lower happiness and satisfaction with life in the long run (Stack, 2012). Moreover, divorce experience negatively affects the compatibility of couples and their children in all psychological, physical, social, and emotional aspects and causes poor performance and inefficiency of the whole family (Portes, Smith, \& Brown, 2000). Divorce increas- 
es the rates of economic, physical, and mental problems for the entire family (Sbarra, Emery, Beam, \& Ocker, 2014). It has been also pointed out that divorce can dispose of many other social problems like suicide (Stack \& Scourfield, 2013), addiction, crime, psychosis, personality conflicts, and major depression (Sbarra et al., 2014).

Harms after divorce can bring the society several problems whose resolving is not easier than the preventing the divorce itself (Cregger et al., 2008). Although divorce is not simply possible because of many cultural and traditional issues and even legal restrictions, many couples are living in families where emotional divorce is dominant. Emotional divorce is a latent and unregistered phenomenon in the life of many couples in which they are not officially separated; however, they live together just as roommates without any feeling and emotion to one another (Ashrafi, 2009). In other words, some marriages become senseless and emotionless without love, intimacy, and friendship that continues just with the flow of family life (Ghaffarzadeh \& Nazari, 2012).

Researchers believe that emotional divorce involves a loss of mutual trust, respect, and love. Here, couples attempt to hurt and frustrate each other and relegate each other's self-esteem rather than to support each other. In addition, each spouse seeks to find some proof of fault, failure, and rejection of another one (Lauer \& Lauer, 2004). In addition to the mentioned items, other conditions such as family involvement, improper upbringing methods, living with the husband's family, husband's employment status, husband's addiction, living in another city, husband's second marriage, lack of commitment, betrayal, arguments, conflicts (Scott, Rhoades, Stanley, Allen, \& Markman, 2013) and unemployment (Cohen, 2014) can be referred to as the causes of emotional divorce and subsequent formal divorce. Bohannon believed that emotional divorce is the first step in formal divorce process; therefore, it is possible to prevent formal divorce by the identification of emotional divorce and provision of appropriate tools to identify couples with emotional divorce. Hence, it is necessary to assess the degree of emotional divorce among couples.

Given the absence of any valid and reliable instrument in accordance with local contexts to measure emotional divorce, Gottman Emotional Divorce Scale (EDS) and Phil Relationship Health Profile Test (RHPT) are often used to measure and study emotional divorce in Iranian society. Gottman (1998) cited in Mousavi \& Rahiminejad (2015) has 24 items and measures emotional divorce as a four-dimension instrument (sense of separation from each other, sense of loneliness, the need for a compan- ion, and boredom and restlessness). The items are answered on a two-choice option, i.e. Yes (1) and No (0) .

Phil RHPT (2005) includes 62 items and assesses individual, private, and social events of marriage. In this questionnaire, there are two options of true and false for each question (Imanpour, Aliloo, Madani, \& nd Haghighat, 2014). Thus, the first step in the prevention of emotional divorce is to identify it according to the above-mentioned fundamental principles and theories and considering the fact that divorce threatens family health. In addition, counseling a difficult task as time is short for both clients and consultants and a great number of people experiencing emotional divorce seek to improve their sexual relationships and solve interpersonal conflicts.

The use of self-assessment tools helps clinical staff achieve relatively sufficient and appropriate knowledge about the clients in an appropriate time. Many of the factors causing marital dissatisfaction and divorce in cultural and social contexts of Iranian couples are different from those in the context of Western cultures (Mohsenzadeh, Nazari \& Arefi, 2011). Hence, a scientific instrument is needed to detect emotional divorce based on Iranian culture to identify people exposed to this social problem and to establish a basis for future research. Therefore, the current study is an attempt to construct and validate EDS for Iranian couples.

\section{Methods}

A descriptive correlational research design was used to conduct this study. Morgan Table was used to determine the sample size. Accordingly, the sample size was 384 , so 400 married individuals living in East Tehran between May and June 2016 were selected by random cluster sampling method to respond to the research instruments. A sample size of 300 units was considered an acceptable level for the conduct of factor analysis (Comry, 1973; Kass \& Tinsley, 1979 cited in Houman, 2001).

In this research, 400 questionnaires were administered in order to ensure the collection of a sufficient number of completed questionnaires. In terms of sampling, the east part of Tehran (based on the municipal demarcation) was first divided into 5 districts. In the next step, 8 streets were randomly selected from each district and 10 house numbers (a total of 400 numbers) were randomly selected from each street. The questionnaires were completed by personal visit of the researcher at the doors of the houses. The criteria for the inclusion of participants in the study were being married, literate, having wife, no 
history of psychiatric disorder according to the respondent, and consent to participate in the research.

The exclusion criteria were the incomplete filling of the questionnaire, unwillingness to respond to the questionnaire items, and reluctance to continue the study despite expressing initial consent. It is noteworthy that 70 questionnaires were excluded due to the lack of cooperation of some of the respondents and flaws in responses despite the provision of adequate explanations to the participants and obtaining of their consent for participating in the study. Therefore, the data in 330 questionnaires were considered for statistical analyses. For the assessment of the convergent and divergent validity of the questionnaire, the researcher-made questionnaire was simultaneously correlated with Phil RHPT and Enrich Marital Satisfaction Scale (MSS). In the end, the data were analyzed in SPSS V. 22 and LISREL V. 8.80.

Emotional Divorce Scale was used. Based on the conduct of preliminary studies and the absence of any appropriate instrument with satisfactory reliability and validity, a relevant preliminary questionnaire was prepared by reviewing the existing literature, interviews with the divorce volunteers, divorcees, and the students and professors expert in the field of emotional divorce. The main objective of this exploration was to extract the materials and components that had been previously raised about emotional divorce in already proposed theories and studies. At this stage, 85 items were chosen for emotional divorce that entailed three factors. The items were scored based on a 5 -point Likert scale ( $1=$ strongly agree, $2=$ agree, $3=$ no idea, $4=$ disagree, and $5=$ strongly disagree).

The factor structure of the scale was investigated using confirmatory factor analysis. The results of factor analysis showed that EDS has been composed of three factors. The three-factor structure of the scale was confirmed by goodness-of-fit indexes. Concurrent administration of the Emotional Divorce Scale with Phil RHPT and Enrich MSS was used to evaluate the convergent and divergent validity of the instrument. The mentioned variables and the obtained data were concurrently analyzed using Pearson correlation coefficient in the sample group. The results of the Pearson correlation indicated that the total score of EDS was significantly correlated with RHPT (0.69) and Enrich MSS (-0.42) at the significance level of $0.01(\mathrm{P} \leq 0.01)$. The reliability of the total scale was equal to 0.973 and the reliability coefficients of the three factors, namely compulsory living, the absence of romantic behavior towards spouse, and emotional vacuum were obtained $0.974,0.730$, and 0.930 values, respec- tively. More detailed information is provided in the procedure and results section.

Phil Relationship Health Profile Test is a 62-item inventory and investigates individual, private, and social events of marriage. In this questionnaire, there are two options of true and false for each question. In terms of scoring, each correct answer to even items receives one point and the sum of these points is considered the total score of the participant. In the introduction to the questionnaire, Phil has described the cut-off points as follows: 1 . Scores above 32 represent a falling relationship; 2. Scores between 20 and 32 represent emotional divorce; 3 . Scores between 12 and 19 represent an imperfect relationship that needs work and effort, but is higher than the mean score of the population; and 4. Scores equal to and smaller than 11 indicate a relationship that is far better than the mean score of the population and does not need any intervention. In Iran, Imanpour et al. (2014) translated this questionnaire and explored its psychometric properties. The Cronbach alpha correlation of the scale has been reported equal to 0.93 . In addition, the test-retest reliability of the questionnaire within a twoweek interval was obtained as 0.78 .

Enrich Marital Satisfaction Scale has been used as a valid instrument for the measurement of marital satisfaction in several studies. It has been designed by Olson, Fornir, and Draken, and its main version consists of 115 items with 12 subscales. The items are scored based on a 5-point Likert scale from strongly agree to strongly disagree. In this study, Enrich 47-item version with the reliability of 0.95 was used. In this version, the obtained scores lower than 30 indicate strong dissatisfaction of couples, scores between 30 and 40 indicate dissatisfaction of couples, scores between 40 and 60 indicate moderate satisfaction of couples, scores between 60 and 70 indicate high satisfaction of couples and scores above 70 indicate very high satisfaction of couples with marital relationships (Sanaee, 2000). In Iran, Soleimanian (1994) translated this questionnaire and explored its psychometric properties. The Cronbach $\alpha$ of the scale has been reported as 0.95 .

Study Procedure was prepared by reviewing the existing literature, interviews with the divorce volunteers, divorcees, and the expert students and professors in the field of emotional divorce. The list of prepared questions on the detection of emotional divorce was given to 10 psychologists to check their content validity. The items receiving confirmation by $80 \%$ of the experts were maintained. On the other hand, the items that were not confirmed by the experts or received no acceptable con- 
sensus were eliminated or reconsidered. It is worth mentioning that there were 85 initial questions, reduced to 55 items after this stage. In the first phase, this instrument was administered to a sample of 50 students. The results of this analysis indicated that all items had an appropriate correlation with their respective scales.

The final analysis was performed with 55 items. Different measures were taken to observe the research ethics as follows: 1. The sufficient description of the research objectives and importance was presented to the participants; 2 . The consent form of research participation was completed by the participants; 3 . The participants were requested to refrain from mentioning their name; 4 . The participants were informed that participation in the research is a voluntary act and they are allowed to leave the research whenever they want; 5. The participants were assured that the collected data through questionnaires would be kept confidential.

For data analysis, the indexes of descriptive statistics, including mean and standard deviation as well as inferential statistics, including confirmatory factor analysis to examine the factor structure of the questionnaire, the Cronbach $\alpha$ coefficient for reliability check, and Pearson correlation coefficient for the examination of validity were used. The results are presented in the following section.

\section{Results}

Before the conduct of relevant data analyses, the overall situation of the data was examined. First, the outliers were identified by referring to the original questionnaires and necessary modifications were made. Then, the unanswered items were replaced by the mean score value of the same item. Thereafter, confirmatory factor analysis was performed on the data as follows as the self-made questionnaire was to measure three factors.

Confirmatory factor analysis: This analysis was used to fit the three-factor model of emotional divorce. As per Thompson (2004), a subset of fit indexes, including Chi-Square $\left(\chi^{2}\right)$, Normed Fit Index (NFI), Comparative Fit Index (CFI), and Root Mean Square Error of Approximation (RMSEA) were calculated. The NFI and CFI values can range from 0 to 1 . The values equal to and above 0.95 are considered acceptable. In the current study, NFI and CFI values were equal to 0.96 and 0.97 , respectively. Therefore, these values were acceptable. RMSEA shows the remaining average values between the observed correlation/covariance of the sample and the estimated model of the population. Loehlin (2004) regarded the values smaller than 0.08 representative of good fit, between 0.08 and 0.10 representative of moderate fit, and the values above 0.10 indicative of low fitness level. In this study, RMSEA value was obtained as 0.10 , which indicates the moderate fit of the model. In this model, $\chi^{2}=2703.36, \mathrm{df}=591$, and $\chi^{2} / \mathrm{df}=4.57$. Overall, the results showed that the model has a suitable fit. Factor loads are presented in Figure 1.

\section{Instrument validity}

Concurrent administration of the Emotional Divorce Scale with Phil RHPTand Enrich MSS was used to evaluate the convergent and divergent validity of the instrument. The mentioned variables and the obtained data were concurrently analyzed using Pearson correlation coefficient in the sample group. Based on the Table 1 results, the total score of Emotional Divorce Scale is significantly correlated with Phil RHPT (0.69) and Enrich MSS (-0.42) at $\mathrm{P} \leq 0.01$. Similarly, each of the subscales

Table 1. Correlation of Emotional Divorce Scale with research variables $(n=330)$

\begin{tabular}{|c|c|c|c|c|c|c|c|}
\hline Variable & Mean $\pm S D$ & 1 & 2 & 3 & 4 & 5 & 6 \\
\hline Compulsory living & $57.40 \pm 25.48$ & 1 & & & & & \\
\hline $\begin{array}{c}\text { Absence of romantic } \\
\text { behavior }\end{array}$ & $17.78 \pm 5.43$ & $0.50^{*}$ & 1 & & & & \\
\hline Emotional vacuum & $30.51 \pm 11.33$ & $0.63^{*}$ & $0.81^{*}$ & 1 & & & \\
\hline Total emotional divorce & $105.70 \pm 38.96$ & $0.87^{*}$ & $0.66^{*}$ & $0.91^{*}$ & 1 & & \\
\hline $\begin{array}{c}\text { Phil Relationship Health } \\
\text { Profile Test }\end{array}$ & $20.43 \pm 11.34$ & $0.20^{*}$ & $0.19^{*}$ & $0.16^{* *}$ & $0.69^{*}$ & 1 & \\
\hline Marital satisfaction & $163.25 \pm 34.57$ & $-0.37^{*}$ & $-0.27^{*}$ & $-0.30^{*}$ & $-0.42^{*}$ & -0.35 & 1 \\
\hline
\end{tabular}




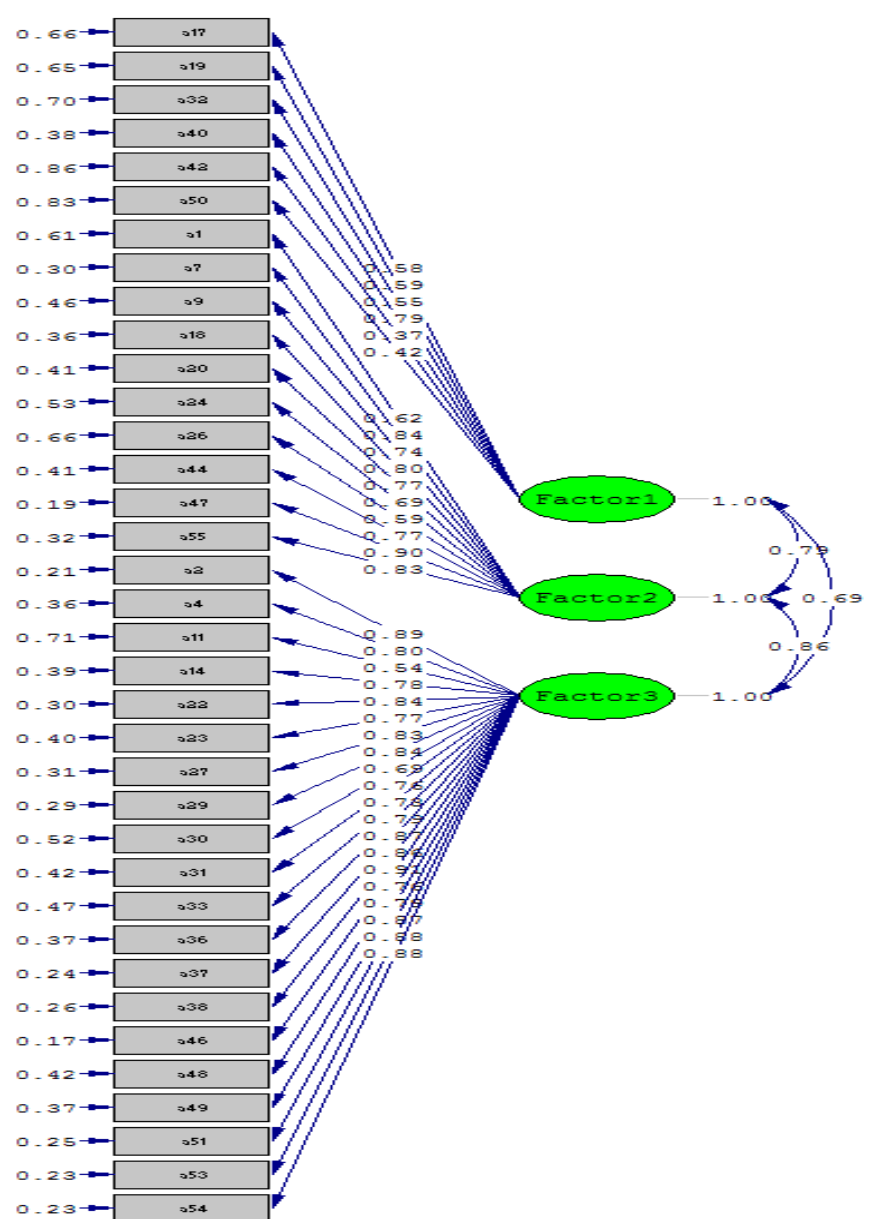

Figure 1. The final measurement model of Emotional Divorce Scale (standardized coefficients were reported)

was significantly correlated with Phil RHPT and Enrich MSS. Table 2 presents the other correlation results.

Reliability of Emotional Divorce Scale calculated using internal consistency and Cronbach $\alpha$ coefficient. In the Table 2, the mean, standard deviation, and correlation of each item with the total score and alpha coefficients in case of the removal of any item are presented. The mean and standard deviation for all items are presented in the Table 2. The results indicate that the reliability coefficients of the total scale, compulsory living with hatred, the absence of romantic behavior towards spouse, and emotional vacuum are 0.973, 0.974, 0.730, and 0.930 , respectively. Thus, the reliability coefficients are acceptable, which indicate the high reliability of the instrument. In addition, the correlation of each item with the total score has been presented in the other column of Table 2 where the results are indicative of the appropriateness of all the correlations (higher than 0.38). Moreover, $\alpha$ coefficients, in case of the removal of each item, are presented in the Table 2. As it is observed, $\alpha$ value decreases when each item is removed. Hence, none of the items were excluded from the questionnaire.

\section{Discussion}

Emotional divorce involves the loss of mutual trust, respect, and love. In emotional divorce, the couples, rather than support, hurt and frustrate each other. Each of the couples tries to find fault with the other one, fail and reject the other one (Lauer \& Lauer, 2004). Accordingly, the assessment of emotional divorce is of high importance. For this reason, the present study aimed to construct and validate EDS in couples.

To this end, EDS was designed and developed based on the theoretical foundation, the related literature, interviews with the divorce volunteers, divorcees, and the students and professors expert in the field of emotional divorce. Thereafter, the content validity of the designed questionnaire was explored via expert opinion and finally confirmed. In the next stage, the questionnaire was piloted on a sample of 50 students and its content 
Table 2. Mean, SD, and correlation of each item with the total score and a coefficients in case of the removal of any item

\begin{tabular}{|c|c|c|c|c|}
\hline Factor & Item & Mean \pm SD & Correlated Item Total Correlation & Cronbach $\alpha$ if Deleted \\
\hline \multirow{6}{*}{ 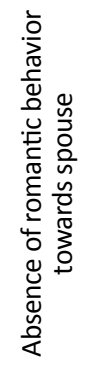 } & 17 & $2.88 \pm 1.47$ & 0.424 & 0.706 \\
\hline & 19 & $2.94 \pm 1.37$ & 0.517 & 0.678 \\
\hline & 32 & $3.08 \pm 1.36$ & 0.469 & 0.692 \\
\hline & 40 & $2.78 \pm 1.41$ & 0.605 & 0.650 \\
\hline & 42 & $2.94 \pm 1.40$ & 0.384 & 0.716 \\
\hline & 50 & $3.15 \pm 1.29$ & 0.398 & 0.711 \\
\hline \multirow{20}{*}{ 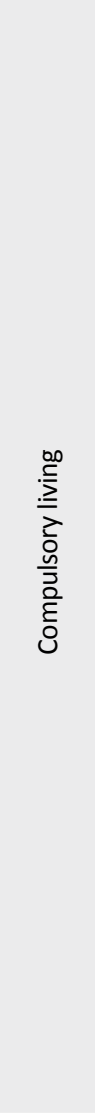 } & 2 & $2.86 \pm 1.63$ & 0.872 & 0.972 \\
\hline & 4 & $2.76 \pm 1.69$ & 0.807 & 0.972 \\
\hline & 11 & $3.07 \pm 1.32$ & 0.519 & 0.975 \\
\hline & 14 & $2.84 \pm 1.61$ & 0.770 & 0.973 \\
\hline & 22 & $2.81 \pm 1.65$ & 0.839 & 0.972 \\
\hline & 23 & $2.94 \pm 1.47$ & 0.763 & 0.973 \\
\hline & 27 & $2.67 \pm 1.64$ & 0.828 & 0.972 \\
\hline & 29 & $2.81 \pm 1.55$ & 0.827 & 0.972 \\
\hline & 30 & $2.82 \pm 1.62$ & 0.694 & 0.974 \\
\hline & 31 & $2.91 \pm 1.54$ & 0.753 & 0.973 \\
\hline & 33 & $2.90 \pm 1.46$ & 0.718 & 0.973 \\
\hline & 36 & $2.83 \pm 1.64$ & 0.792 & 0.973 \\
\hline & 37 & $2.82 \pm 1.52$ & 0.855 & 0.972 \\
\hline & 38 & $2.95 \pm 1.59$ & 0.838 & 0.972 \\
\hline & 46 & $2.79 \pm 1.64$ & 0.900 & 0.971 \\
\hline & 48 & $2.92 \pm 1.51$ & 0.772 & 0.973 \\
\hline & 49 & $2.98 \pm 1.54$ & 0.768 & 0.973 \\
\hline & 51 & $2.90 \pm 1.56$ & 0.846 & 0.972 \\
\hline & 53 & $2.80 \pm 1.73$ & 0.865 & 0.972 \\
\hline & 54 & $3.00 \pm 1.66$ & 0.854 & 0.972 \\
\hline \multirow{10}{*}{ 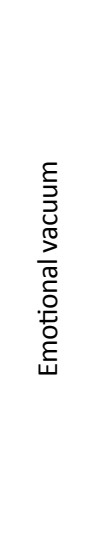 } & 1 & $2.97 \pm 1.46$ & 0.590 & 0.930 \\
\hline & 7 & $3.03 \pm 1.49$ & 0.793 & 0.920 \\
\hline & 9 & $3.01 \pm 1.42$ & 0.700 & 0.924 \\
\hline & 18 & $3.03 \pm 1.39$ & 0.762 & 0.921 \\
\hline & 20 & $3.04 \pm 1.53$ & 0.730 & 0.923 \\
\hline & 24 & $3.03 \pm 1.34$ & 0.676 & 0.926 \\
\hline & 26 & $3.09 \pm 1.39$ & 0.601 & 0.929 \\
\hline & 44 & $3.19 \pm 1.43$ & 0.754 & 0.922 \\
\hline & 47 & $2.99 \pm 1.50$ & 0.856 & 0.916 \\
\hline & 55 & $3.12 \pm 1.49$ & 0.809 & 0.919 \\
\hline
\end{tabular}


validity was confirmed. In the final step, it was administered to the whole sample and a number of the questions with weak correlation with the total score $(>0.3)$ were excluded from the scale. Confirmatory factor analysis, Pearson correlation, and Cronbach $\alpha$ reliability analysis were done on the rest of the items.

Given that the three-factor model of emotional divorce had been raised, confirmatory factor analysis was performed on the data. Data analysis showed that the EDS confirms the three-factor structure with suitable fit indexes. Furthermore, the Pearson correlation was used to investigate the convergent and divergent validity of the scale where the results indicated that the scale and its factors had a negative significant correlation with marital satisfaction and a positive significant correlation with Phil RHPT. These findings are consistent with the results of other studies (Safayi Rad \& Varastehfar, 2012; Kafashi \& Sarabadani, 2014; Talebpour, Vaziri, \& Marzdarani, 2015).

The marriages that end in divorce aggravate the economic, physical, and mental problems of the entire family (Sbarra, Law, \& Portley, 2011). Divorce can also bring about many other problematic issues, such as suicide (Stack \& Scourfield, 2013) addiction, crime, psychosis, personality conflicts, and major depression (Sbarra et al., 2014). It can be also claimed that the trauma after divorce would engage the society in many problems where the resolving of each is much more difficult than that of divorce itself (Strong, 2008). Guven, Senik andStichnoth (2012) examined the gap between happiness and divorce. They used the results of three longitudinal studies in Germany, the UK, and Australia between 1984 and 2007. Their results indicate that the happiness gap between couples is a good predictor of divorce in the future.

The effects of happiness gap are asymmetric, which means that when the wives are less happy than the husbands, the couples are more inclined to separation. The more the emotional distance, the less happiness is observed. The unhealthy and hateful relationships between spouses undermine the foundation of the family and bring distance between them. Such a lifestyle has many negative consequences for spouses, children, and society. The prevention of emotional divorce and official divorce is very important and this important point comes true with the diagnosis of emotional divorce among couples. In this way, both formal divorce and its negative consequences can be prevented. In addition to what was discussed, internal consistency and Cronbach $\alpha$ methods were used to calculate the reliability of EDS. Based on the results, the reliability of the total scale and each of its subscales were satisfactory. This represents the high reliability of the instrument.

There is no research without limitations. First, it is not clear to what extent the scores obtained from this instrument are related to actual behaviors in everyday life. The second limitation of the study pertains to the spatial and temporal scope of the study. This study has been done on couples living in eastern part of Tehran; therefore, its findings cannot be generalized to the people in other cities.

For any generalization, care and discretion should be exercised. Based on these limitations, it is recommended that emotional divorce scores be correlated with measures of actual behavior in everyday life so that more evidence for the expansion of these scores be obtained based on the application of this instrument in real life situations. This means that it is not still clear whether or not high scores on this questionnaire can predict real behaviors. In addition, researchers are recommended to plan their future studies so that they can recognize the practical applications of this instrument in predicting actual behavior in real life. Additionally, the evaluation of the validity of the scale scores as a tool for the identification of sensitive effects can be another focus of the required research for this scale.

It is also suggested that the relationship of emotional divorce be examined with different variables, including mental health, life satisfaction, happiness, addiction, family cohesion, attachment styles, loneliness, and suicide so that a coherent body of knowledge be obtained regarding emotional divorce and its relations with other constructs that are more capable in relevant planning. Finally, the current researchers express their gratitude to all participants for their trust and sincere cooperation.

Considering the ease of administration, scoring, interpretation, as well as suitable validity and reliability of the scale, it is a proper instrument for the assessment of emotional divorce among couples. Considering the prevalence of divorce in our country and to prevent its further spread, experts can identify the people at risk of this issue by this instrument and prevent the spread of divorce via taking necessary measures.

\section{Ethical Considerations}

\section{Compliance with ethical guidelines}

All ethical principles were considered in this article. The participants were informed about the purpose of the research and its implementation stages; they were also assured about the confidentiality of their information; 
Moreover, They were allowed to leave the study whenever they wish, and if desired, the results of the research would be available to them.

\section{Funding}

The present paper was extracted from the MSc. thesis of the first author in Department of Psychology, Faculty of Psychology \& Educational Sciences, Semnan University.

\section{Authors contributions}

All authors contributed in preparing this article.

\section{Conflict of interest}

The authors declared no conflict of interest.

\section{Acknowledgements}

We would like to thank the Higher Education Committee of Semnan University.

\section{References}

Amato, P. R. (2010). Research on divorce: Continuing trends and new developments. The Journal of Marriage and Family, 72(3), 650-66. [DOI:10.1111/j.1741-3737.2010.00723.x]

Ashrafi, F. A. (2009). [Sociological study of emotional divorce (Case Study: Tehran $6^{\text {th }}$ municipal district) (Persian)] [MA. thesis]. Tehran: Islamic Azad University, Science and Research Branch.

Cohen, P. N. (2014). Recession and divorce in the United States, 2008-2011. Population Research and Policy Review, 33(5), 615-28. [DOI:10.1007/s11113-014-9323-z]

Etzion, D., \& Romi, S. (2015). Typology of youth at risk. Children and Youth Services Review, 59, 184-95. [DOI:10.1016/j.childyouth.2015.10.017]

Feldhaus, M., \& Heintz-Martin, V. (2015). Long-term effects of parental separation: Impacts of parental separation during childhood on the timing and the risk of cohabitation, marriage, and divorce in adulthood. Advances in Life Course Research, 26, 22-31. [DOI:10.1016/j.alcr.2015.07.003]

Fouladchang, M. (2006). [The role of the family structure in adolescent's adaptation (Persian)]. Journal on Family Research, 2(7), 209-21.

Ghaffarzadeh, S. M., \& Nazari, H. (2012). The consequences of divorce on individual, family and society. Life Science Journal, 9(4), 281-5.

Guven, C., Senik, C., \& Stichnoth, H. (2012). You can't be happier than your wife: Happiness gaps and divorce. Journal of Eco- nomic Behavior and Organization, 82(1), 110-30. [DOI:10.1016/j. jebo.2012.01.003]

Hamama, L., \& Ronen-Shenhav, A. (2012). Self-control, social support, and aggression among adolescents in divorced and two-parent families. Child and Youth Services Review, 34(5), 1042-9. [DOI:10.1016/j.childyouth.2012.02.009]

Houman, H. A. (2001). [Multivariate data analysis in behavioral research (Persian)]. Tehran: Parsa Pub.

Imanpour, T., Mahmood Aliloo, M., Madani, Y., \& Haghighat, M. (2014). [Psychometric properties of Phil Relationship Health Profile Test among couples in Urmia (Persian)]. Tehran: Family Psychology Association of Iran.

Kafashi, M., \& Sarabadani, S. (2014). [Socio-economic factors effective in emotional divorce between married housewives and married employed women in Qom City (Persian)]. Journal of Contemporary Sociological Research, 3(5), 125-53.

Koerner, A. F., \& Maki, L. (2004). Family communication patterns and social support in families of origin and adult children's subsequent intimate relationships. Paper presented at The International Association for Relationship Research Conference, Madison, Wisconsin, United States, 22-25 July 2004. [PMCID]

Lauer, R. H., \& Lauer, J. C. (2004). Marriage and family: The quest for intimacy. New York: McGraw-Hill Publishing Company, Inc.

Loehlin, J. C. (2004). Latent variable models: An introduction to factor, path, and structural equation analysis ( $4^{\text {th }}$ Edition). Hillsdale, New Jersey: Erlbaum. [PMID]

Mohsenzadeh, F., Nazari, A. M., \& Arefi, M. (2011). [Qualitative study of marital dissatisfaction and divorce attempt (Case Study of Kermanshah) (Persian)]. Womens Strategic Studies, 14(53), 7-42.

Mousavi, F., \& Rahiminejad, A. (2015). [The comparison of interpersonal identity statuses in married people with regards to emotional divorce (Persian)]. Applied Psychological Research Quarterly, 6(1), 11-23.

Okorodudu, G. N. (2010). Influence of parenting styles on adolescent delinquency in delta central senatorial district. Edo Journal of Counselling, 3(1), 58-86. [DOI:10.4314/ejc.v3i1.52682]

Portes, P. R., Smith, T. L., Brown JH. (2000). The divorce adjustment inventory-revised: Validation of a parental report concerning children's post-custody adjustment. Journal of Divorce E Remarriage, 33(3-4), 93-109. [DOI:10.1300/J087v33n03_06]

Rezayi, J., \& Naraghi, A. (2010). [Study of the pattern of healthy families in tradition of Prophet of Islam (PBUH) (Persian)]. Qur'anic Studies Journal, 1(4), 93-124.

Safayi Rad, S., \& Varastehfar, A. (2012). [A survey on the relationship of marital conflicts with emotional divorce of referring women to the court of eastern Tehran in 2011 (Persian)] Journal of Social Research, 5(20), 85-106.

Sanaee, B. (2000). [Measures of family and marriage (Persian)]. Tehran: Be'esat Pub.

Sbarra, D. A., Emery, R. E., Beam, C. R., Ocker, B. L. (2014). Marital dissolution and major depression in midlife: A propensity score analysis. Clinical Psychological Science, 2(3), 249-57. [DOI:10.1177/2167702613498727] 
Sbarra, D. A., Law, R. W., \& Portley, R. M. (2011). Divorce and death: A meta-analysis and research agenda for clinical, social, and health psychology. Perspectives on Psychological Science, 6(5), 454-74. [DOI:10.1177/1745691611414724]

Scott, S. B., Rhoades, G. K., Stanley, S. M., Allen, E. S., Markman, H. J. (2013). Reasons for divorce and recollections of premarital intervention: Implications for improving relationship ducation. Couple and Family Psychology: Research and Practice, 2(2), 131-45. [DOI:10.1037/a0032025]

Soleimanian, A. (1994). [The investigation of irrational thinking based on the cognitive approach on the marital dissatisfaction (Persian)] [MSc. thesis]. Tehran: Tarbiat Moalem University.

Stack, S. (2012). Encyclopedia of human behavior (2 ${ }^{\text {nd }}$ Edition). Cambridge, Massachusetts: Academic Press. [DOI:10.1016/B9780-12-375000-6.00136-1]

Stack, S., Scourfield, J. (2013). Recency of divorce, depression, and suicide risk. Journal of Family, 36(6), 695-715. [DOI:10.1177/0192513X13494824]

Strong, B. (2008). The marriage and family experience. Belmont Ontario: Thomson Higher Education 10 Davis Drive. [DOI:10.1111/j.1752-0606.2008.00079.x] [PMID]

Talebpour, A., Vaziri, H., \& Marzdarani, H. (2015). [Evaluation affecting factors of emotional divorce (Case study: The perspective of higher education married staffs in Karaj Province in 2014) (Persian)]. MAGNT Research Report, 3(3), 459-67.

Thompson, B. (2004). Exploratory and confirmatory factor analysis: Understanding concepts and applications. Washington, D. C.: American Psychological Association. [DOI:10.1037/10694-000] 